\title{
The Use of Data to Assist in the Design of a New Service System for Homeless Veterans in New York City
}

\section{Claire Henderson · Jay Bainbridge · Kim Keaton · Martha Kenton • Meghan Guz $\cdot$ Becky Kanis}

\section{Erratum to: Psychiatr Q \\ DOI 10.1007/s11126-007-9060-0}

The following reference to unpublished data should be added to the last sentence in the paragraph in the Results section entitled Data from Street Outreach:

6. Levitt AJ: Needs assessment of Manhattan street homeless adults, 2007

The online version of the original article can be found under doi:10.1007/s11126-007-9060-0.

C. Henderson $(\bowtie)$

Evaluation and Health Services Research, VISN 3 MIRECC, James J. Peters VA Medical Center, 130 West Kingsbridge Road, Bronx, NY 10468, USA

e-mail: Rosalind.Henderson@va.gov

J. Bainbridge

Policy and Research, New York City Department of Homeless Services, New York, NY, USA

K. Keaton · M. Guz

Quality Assurance, Program Evaluation and Policy Analysis Unit, Division of Adult Services, New York City Department of Homeless Services,

New York, NY, USA

M. Kenton

Technical Assistance and Training Division of Adult Services, New York City Department of Homeless Services, New York, NY, USA

B. Kanis

Innovations, Common Ground Community, New York, NY, USA 